\title{
Influence of Sonication on the Stability and Thermal Properties of $\mathrm{Al}_{2} \mathrm{O}_{3}$ Nanofluids
}

\author{
Monir Noroozi, ${ }^{1}$ Shahidan Radiman, ${ }^{1}$ and Azmi Zakaria ${ }^{2}$ \\ ${ }^{1}$ School of Applied Physics, Faculty of Science and Technology, Universiti Kebangsaan Malaysia (UKM), 43600 Bangi, \\ Selangor, Malaysia \\ ${ }^{2}$ Department of Physics, Faculty of Science, Universiti Putra Malaysia (UPM), 43400 Serdang, Selangor, Malaysia
}

Correspondence should be addressed to Monir Noroozi; monir.noroozi@gmail.com

Received 2 September 2014; Revised 11 November 2014; Accepted 11 November 2014; Published 11 December 2014

Academic Editor: William W. Yu

Copyright (C) 2014 Monir Noroozi et al. This is an open access article distributed under the Creative Commons Attribution License, which permits unrestricted use, distribution, and reproduction in any medium, provided the original work is properly cited.

\begin{abstract}
Nanofluids containing $\mathrm{Al}_{2} \mathrm{O}_{3}$ nanoparticles (either 11 or $30 \mathrm{~nm}$ in size) dispersed in distilled water at low concentrations (0.125$0.5 \mathrm{wt} \%$ ) were prepared using two different ultrasonic devices (a probe and a bath sonicator) as the dispersant. The effect of the ultrasonic system on the stability and thermal diffusivity of the nanofluids was investigated. Thermal diffusivity measurements were conducted using a photopyroelectric technique. The dispersion characteristics and morphology of the nanoparticles, as well as the optical absorption properties of the nanofluids, were studied using photon cross correlation spectroscopy with a Nanophox analyzer, transmission electron microscopy, and ultraviolet-visible spectroscopy. At higher particle concentration, there was greater enhancement of the thermal diffusivity of the nanofluids resulting from sonication. Moreover, greater stability and enhancement of thermal diffusivity were obtained by sonicating the nanofluids with the higher power probe sonicator prior to measurement
\end{abstract}

\section{Introduction}

The thermal properties of nanofluids play a vital role in the development of high-performance heat-transfer devices [1]. Metal oxide nanofluids have attracted great interest in various areas of nanotechnology, from biological and biomedical applications to a new class of heat-transfer fluids, because of their higher thermal conductivity than the corresponding base fluids [2-6]. The size and particle size distribution (PSD) of nanoparticles (NPs) in nanofluids critically affect their thermal properties because dispersed NPs in a liquid tend to agglomerate and settle [7]. This problem can be eliminated by reducing the size and heterogeneity of the NPs. Several methods have been developed to stabilize nanofluids towards NP aggregation, for example, using electrostatic repulsion [8] or steric stabilization [9]. Physical dispersion of a powder in a liquid can be achieved by ultrasonic irradiation to achieve a homogeneous nanofluid with small-sized particles [10]. The effect of ultrasonic irradiation on nanofluid formation depends on the time, temperature, frequency, and power of the sonicator [11, 12]. Acoustic cavitation induced by sonication results in strong shear forces that can break up agglomerates [13]. In general, acoustic cavitation in liquids can improve diffusion rates, producing highly concentrated and uniform dispersions of micrometer- or nanometersized materials in base fluids $[14,15]$. Nanofluids have been prepared in many studies demonstrating the potential uses of ultrasound baths [16-18]. In contrast to the lower-intensity bath-type sonicators, higher intensity ultrasound probes are typically used to create suspensions and emulsions, as well as in biomedical applications [19-22]. Although sonication is a useful technique to assist the dispersion and stabilization of nanofluids, the influence of the type of ultrasound system (i.e., probe or bath) on the synthesis mechanism of nanofluids is not clear. Moreover, there are very few reports dealing with the effects of sonication on the thermal properties of nanofluids.

Numerous experimental investigations have been carried out to measure the effect of NPs in base fluids on the thermal properties of nanofluids [23]. Although the thermal conductivity of nanofluids has been widely studied in the past few years, little work has been done to determine the most suitable thermal parameters of nanofluids [24-27]. Thermal diffusivity is defined as the thermal conductivity divided by 
the specific heat and density. In general, thermal diffusivity is measured more easily and accurately than the thermal conductivity. The two other relevant properties are density and specific heat, which either are known values or can easily be measured. The photopyroelectric (PPE) technique, using a pyroelectric (PE) sensor in thermal contact with the sample $[28,29]$, has been used as a powerful technique for measuring the thermal diffusivity of liquids with very high precision and resolution [30]. The major advantage of this technique is the fixed noise bandwidth that improves the precision and sensitivity of the system, as well as eliminating the requirement for instrumental transfer function normalization. A PPE experiment is relatively simple to design and the materials that can be investigated vary from weakly to strongly absorbing materials.

In this paper, the effects of sonication type on the stability and thermal properties of $\mathrm{Al}_{2} \mathrm{O}_{3}$ NPs of two different sizes (11 and $30 \mathrm{~nm}$ ) dispersed in distilled water (DW) were examined. The thermal diffusivity enhancement of the $\mathrm{Al}_{2} \mathrm{O}_{3}$ nanofluid was found to be both size and concentration dependent and was much greater when the ultrasonic probe was used instead of the bath. Stabilization mechanisms of the nanofluids were analyzed by photon cross correlation spectroscopy, transmission electron microscopy (TEM), and ultraviolet-visible (UV-vis) spectroscopy. Thermal diffusivity measurements for the nanofluids and base fluid were obtained using the PPE technique.

\section{Materials and Methods}

2.1. Preparation of Nanofluids. $\mathrm{Al}_{2} \mathrm{O}_{3}$ nanopowders of two sizes, size A $(11 \mathrm{~nm})$ and size B $(30 \mathrm{~nm})$, with $99 \%$ purity (Nanostructured and Amorphous Materials, Inc.) were used in this study. In each nanofluid sample, NPs $(0.125,0.25$, or $0.5 \mathrm{wt} \%$ ) were dissolved in DW and magnetically stirred vigorously until a clear solution was observed after about $1 \mathrm{~h}$. Two different ultrasonic systems were chosen to disperse the NPs in the base fluid, namely, a probe-type sonicator (VCX 500; $25 \mathrm{kHz}, 500 \mathrm{~W}$ ) and a bath-type sonicator (Powersonic, UB-405; $40 \mathrm{KHz}, 350 \mathrm{~W}$ ). The total amount of energy delivered to the sample was constant for both sonicators. All nanofluid samples were prepared by a two-step method, in which the NPs were first produced and then dispersed in the base fluids.

The probe sonicator is expected to deliver a higher power $(500 \mathrm{~W})$ to the suspension than the ultrasonic bath $(350 \mathrm{~W})$ because the probe is directly immersed in the suspension. In contrast to bath sonication that was performed at room temperature, the probe sonicator operates at higher amplitudes and is more effective at inducing cavitation and causing heating. Therefore, for experiments using the ultrasonic probe, the nanofluid was placed in a separate container filled with ice to prevent evaporation of the fluid caused by the elevated temperature.

During sonication of a suspension, traditional characterization techniques such as TEM cannot be used to investigate the particle size. For this reason, a Nanophox particle size analyzer (Sympatec GmbH, D-38678) was used to investigate the particle size and distribution of aggregates in the nanofluids. This equipment is based on the principle of dynamic light scattering, where PSD's of the NPs are measured from their velocity owing to Brownian motion using the EinsteinStokes equation [31]. After each round of sonication, the mean particle size and size distributions of the NPs were determined. All samples containing the $\mathrm{Al}_{2} \mathrm{O}_{3}$ nanofluid were diluted to very low concentrations for measurement and were transferred to rectangular glass cells by pipette. The prepared samples were also characterized using UV-vis absorption spectrometer (UV-1650 PC; Shimadzu) over the range of 200-700 nm. The morphology of the alumina clusters was characterized by TEM (H-7100; Hitachi, Tokyo, Japan).

2.2. Photopyroelectric Technique Set-Up. The details of the experimental set-up for thermal diffusivity measurements in liquid samples can be found elsewhere [32]. The nanofluid sample was placed in the volume cell between two parallel walls, a metallic thin foil (50 $\mu \mathrm{m}$ thick) acted as a PE generator, and a $52 \mu \mathrm{m}$ PVDF film (MSI DT1-028 K/L) acted as a PE detector. A $200 \mathrm{~mW}$ CW DPSS (MGL 150(10)) modulated laser beam impinged on the black painted external face of the thin metal foil and converted it to a thermal wave. The PVDF film was fixed with silicon glue to a Perspex substrate. In the cell, the thermal wave propagates across the liquid and reaches the PE detector, which generates a PE signal proportional to the intensity of the thermal wave. The signal generated was sent to a lock-in amplifier (SR530) to increase the PE amplitude. To measure the thermal diffusivity in this technique, the sample, the PE detector, and the backing must be in a thermally thick configuration. To gain information of the sample near the surface [33], it is important to choose the optimal frequency for thermophysical measurements of nanofluids. At frequencies below $7 \mathrm{~Hz}$, the effect of reduced thermal thickness becomes obvious. At very high frequencies, the signal is very small and independent of frequency. Therefore, the frequency range between 7 and $36 \mathrm{~Hz}$ was used for the frequency scan. The thermal diffusivity measurements were performed at room temperature $\left(\approx 20^{\circ} \mathrm{C}\right)$. The noise level in the present set-up was about $75 \mu \mathrm{V}$. LabVIEW software, installed on a PC, was used to capture the amplitude and phase data, which were analyzed using Origin 8. A schematic of the experimental apparatus is shown in Figure 1.

The PE signal $S(f)$ decreases exponentially with increasing modulation of the frequency and can be expressed as follows [34]:

$$
\begin{gathered}
S(f)=S_{0} \exp \left(-(1+i) \frac{L}{\mu}\right), \\
\ln |S(f)|=\ln \left|S_{0}\right|-\frac{L}{\mu}
\end{gathered}
$$

where $S(f)$ is the complex PE signal, $S_{0}$ is a complex constant, and $f$ is the modulation frequency. The thermal diffusion length of sample is $\mu=(\alpha / \pi f)^{1 / 2}$. In the thermally thick regime of the liquid sample, when $L \gg \mu$ [35], the PE signal is determined by the thickness, $L$, and thermal diffusivity of the sample, $\alpha$. From the slope of the linear part 


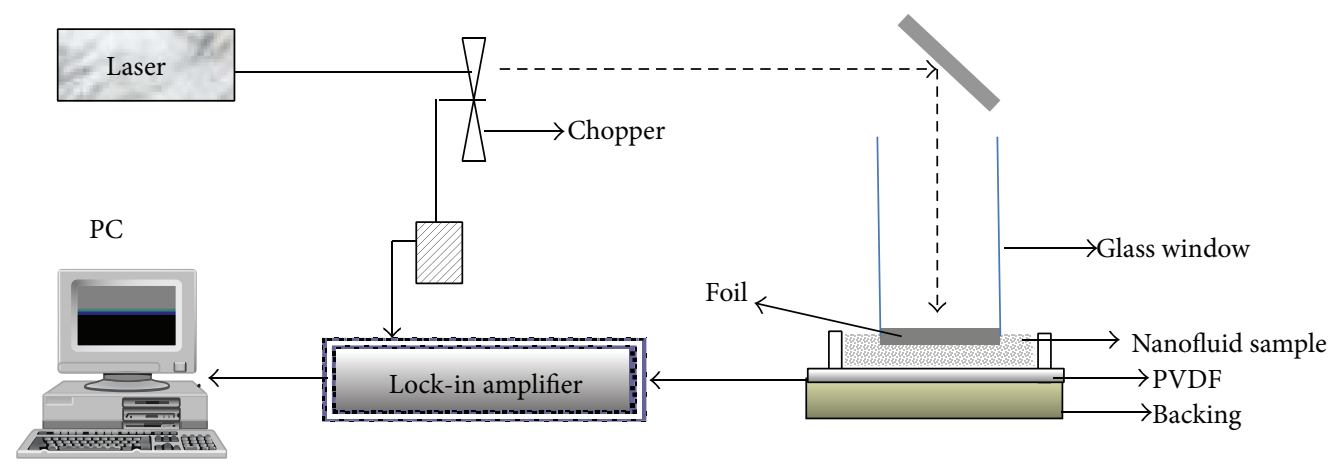

FIGURE 1: Schematic side-view of the photopyroelectric technique.

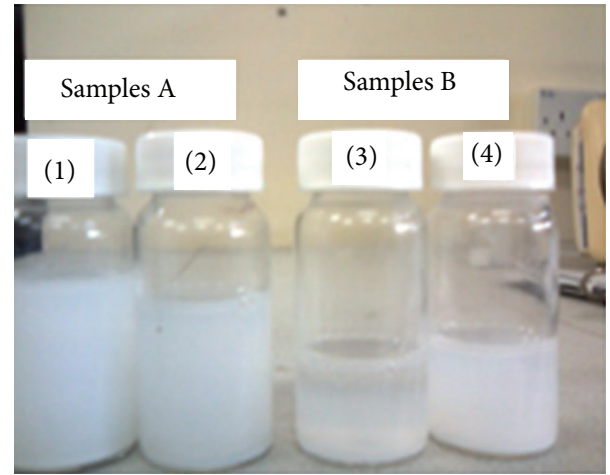

FIGURE 2: $0.5 \mathrm{wt} \% \mathrm{Al}_{2} \mathrm{O}_{3}$ nanofluids 30 days after formulation; right to left are nanofluids prepared from NPs of sizes A and B using the bath (numbers 1 and 3 ) and probe (numbers 2 and 4 ) sonicators.

of the logarithmic amplitude versus $(f)^{1 / 2}$ plot, the thermal diffusivity $\alpha=\pi L^{2} /(\ln |S| / \sqrt{f})^{2}$ can be calculated. A careful calibration of the PPE set-up was carried out by measuring the thermal diffusivity of DW as a reference prior to the actual measurements.

\section{Results and Discussion}

3.1. Characterization and Stability of Nanoparticles. The visual effect of the two sonication systems on $\mathrm{Al}_{2} \mathrm{O}_{3}$ NPs of two sizes (A: $11 \mathrm{~nm} ; \mathrm{B}: 30 \mathrm{~nm}$ ) prepared as $0.5 \mathrm{wt} \%$ nanofluids over a 30-day observation period can be seen in Figure 2. Nanofluids of NPs of sizes A and B prepared using the probe sonicator were observed to be more stable, as shown in Figure 2 (numbers 2 and 4 ).

The larger NPs had a tendency to sediment. It can be seen in Figure 2 (number 3) that the greatest amount of sediment was attained in the nanofluid comprising size B NPs prepared using the bath sonicator. The stability of the nanofluids is size dependent and it has been found that samples prepared under higher intensity sonication are more stable [22].

The $\mathrm{Al}_{2} \mathrm{O}_{3}$ NPs were dispersed in DW using either the bath or the probe sonicators. The hydrodynamic diameter and PSD of the $\mathrm{Al}_{2} \mathrm{O}_{3}$ in the nanofluids were measured three times at 15 min intervals. The dispersions and results of the particle size analysis of these samples are shown in Figure 3. It can be seen that the PSD's for sample A $(11 \mathrm{~nm})$ dispersed in DW using the bath and probe sonicators were in the range of 91-109 nm (Figure 3(a)) and 65-71 nm (Figure 3(b)), respectively. For sample B $(30 \mathrm{~nm})$ dispersed using the bath and probe sonicators, the PSD's were in the range of $83-113 \mathrm{~nm}$ (Figure 3(c)) and 66-90.5 nm (Figure 3(d)), respectively. This can be ascribed to the fact that the clusters were only slightly broken up by the bath sonicator, in contrast to the probe sonicator, which broke these up effectively. The smallest mean hydrodynamic particle diameter was recorded for sample A under probe sonication (Figure 3(b)). With decreasing particle size, the stability of the nanofluids under probe sonication increases, as shown in Figures 3(b) and 2 (number 2). However, in all cases, the measured particle sizes were larger than the nominal particle sizes claimed by the vendor. This indicates that the NPs agglomerated in DW and that the agglomerates were not completely broken up by sonication. The mean of the PSD of the sample dispersed with the bath sonicator (Figure 3(c)) increased with time, reflecting the formation of agglomerates (with hydrodynamic radii larger than $100 \mathrm{~nm}$ ), which are usually observed in unstable solutions. In contrast, the size distribution of the sample dispersed with the probe sonicator (Figure 3(d)) exhibited a significant shift to smaller particle sizes because of the breakup of clusters during sonication. The small discrepancy close to the baseline arises from a few small agglomerates in the nanofluid. Therefore, the suspension remained relatively monodisperse throughout the experiment. The observed narrow size dispersion of the NPs in Figures 3(b) and 3(d) indicates the remarkably high efficiency of treatment with a powerful ultrasonic probe.

Additionally, the differences in the mean particle size observed for dispersion with the different sonicators can provide information about the stability and the degree of dispersion of the nanofluids [25-27]. In Figure 4, it can be observed that, for the nanofluid comprising NPs of size A under probe sonication, there was no significant change in the mean particle size for the three measurements $(65,68$, and $71 \mathrm{~nm}$ ). Moreover, the PSD's were narrow, indicating better dispersion compared with the other nanofluids examined. It 


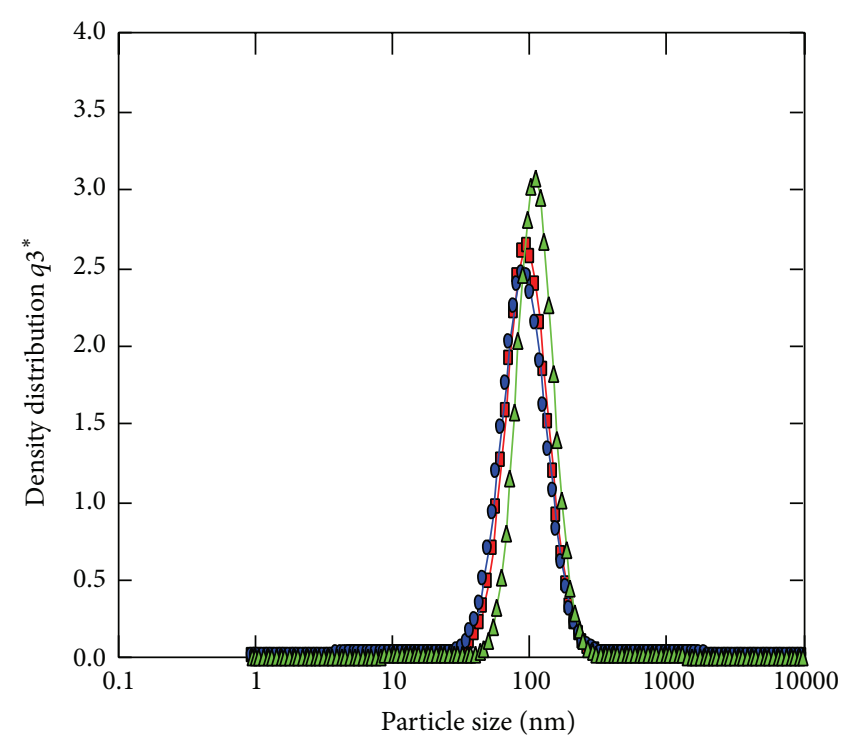

(a)

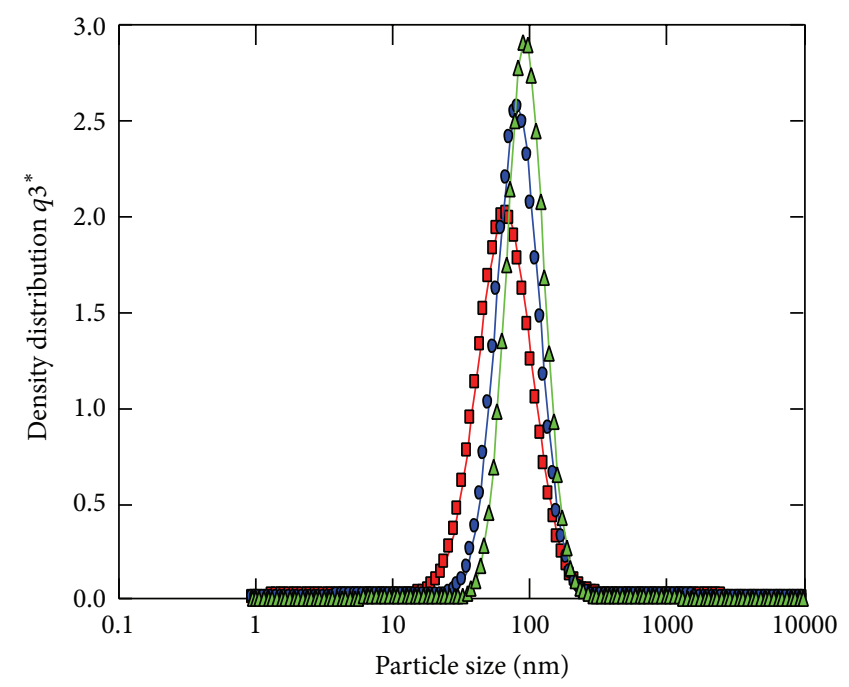

(c)

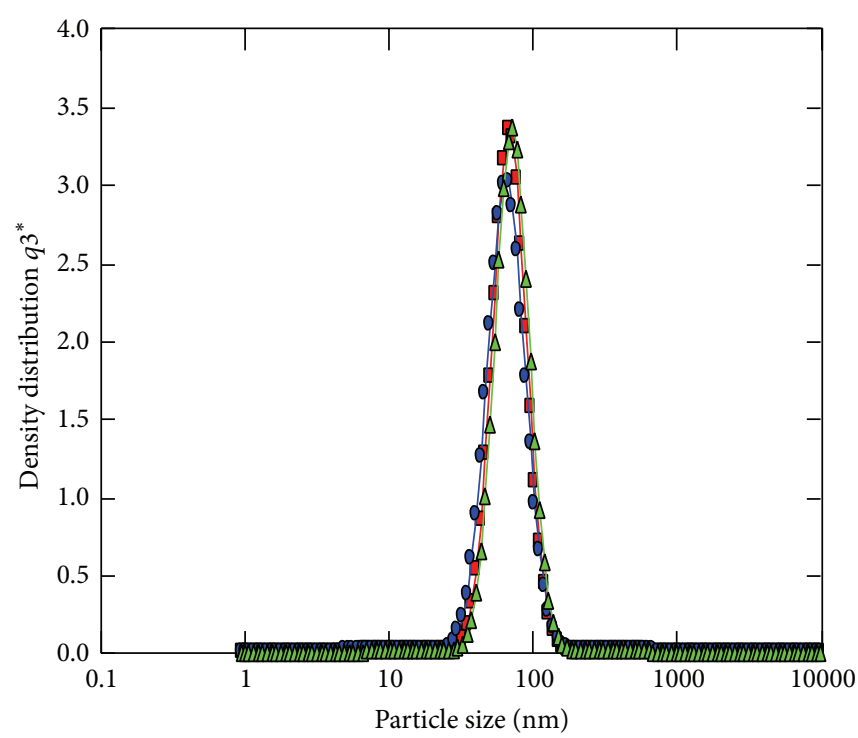

(b)

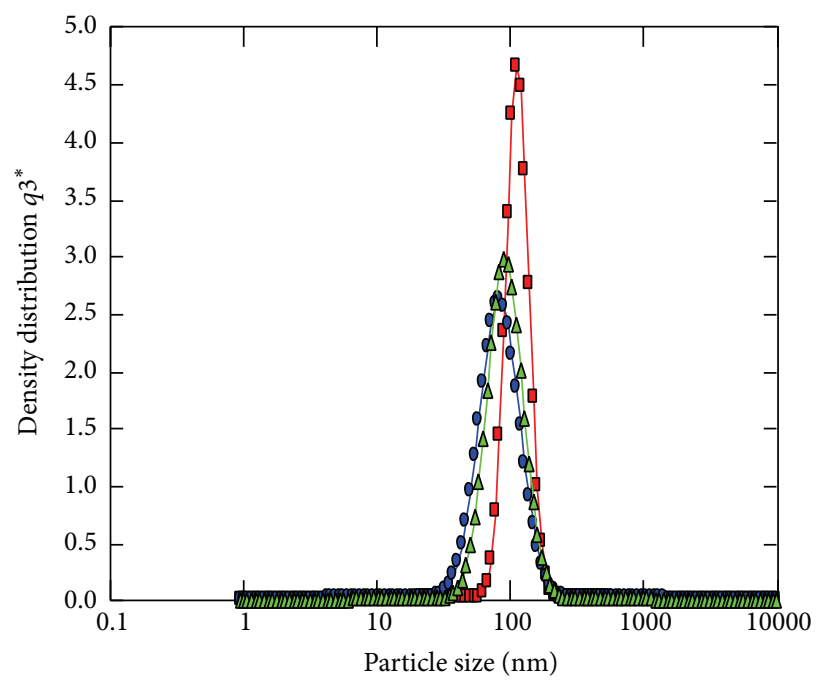

(d)

FIGURE 3: PSD's determined using the Nanophox analyzer of $\mathrm{Al}_{2} \mathrm{O}_{3}$ particles in the nanofluids after three measurements at 15 min intervals, for NPs of sizes A ((a) and (b)) and B ((c) and (d)) prepared using the bath ((a) and (c)) and probe ((b) and (d)) sonicators. PDS just after sonication ( $\square)$, after $15 \mathrm{~min}(\bigcirc)$, and after $30 \mathrm{~min}(\Delta)$.

can be seen that, even in the best-dispersed nanofluid, the particle mean size is seven times the nominal NP size (11 nm). This means that particles in the suspensions aggregate to form large nanoclusters even after ultrasonic treatment. To use the Nanophox analyzer with high resolution, all $\mathrm{Al}_{2} \mathrm{O}_{3}$ nanofluids were diluted to very low concentrations; we believe that the mean diameter and the relative PSD in the Nanophox analyzer are valid for comparisons between powders and dispersion processes [31].

To compare the effect of ultrasonic irradiation on the PSD, the synthesized $\mathrm{Al}_{2} \mathrm{O}_{3}$ nanofluids were analyzed by TEM. Both powders used in the present work consisted of loose agglomerates with sizes greater than $1 \mu \mathrm{m}$, as shown in Figures 5(a) and 5(b). Figures 5(c) and 5(d) show the TEM images of the synthesized $\mathrm{Al}_{2} \mathrm{O}_{3}$ nanofluids $\mathrm{A}(11 \mathrm{~nm})$ and $\mathrm{B}$ $(30 \mathrm{~nm})$, respectively, after treatment with the bath sonicator. Ultrasonic irradiation promotes dispersion of the NPs in DW. The bath sonicator effectively reduced the particle size to below $200 \mathrm{~nm}$. From the TEM images in Figures 5(a)-5(d), it can be seen that the $\mathrm{Al}_{2} \mathrm{O}_{3} \mathrm{NPs}$ are well distributed. The TEM images in Figures 5(e) and 5(f) show the morphology of the synthesized $\mathrm{Al}_{2} \mathrm{O}_{3}$ nanofluids $\mathrm{A}$ and $\mathrm{B}$, respectively, after dispersion using the probe sonicator.

The TEM images of the NPs show that the probe sonicator effectively reduced the particle size to below $100 \mathrm{~nm}$ and that the NPs formed isolated clusters in a stable suspension. Comparing the TEM images for the different sonicators, it can be seen that the bath sonicator (Figures 5(c) and 5(d)) was 


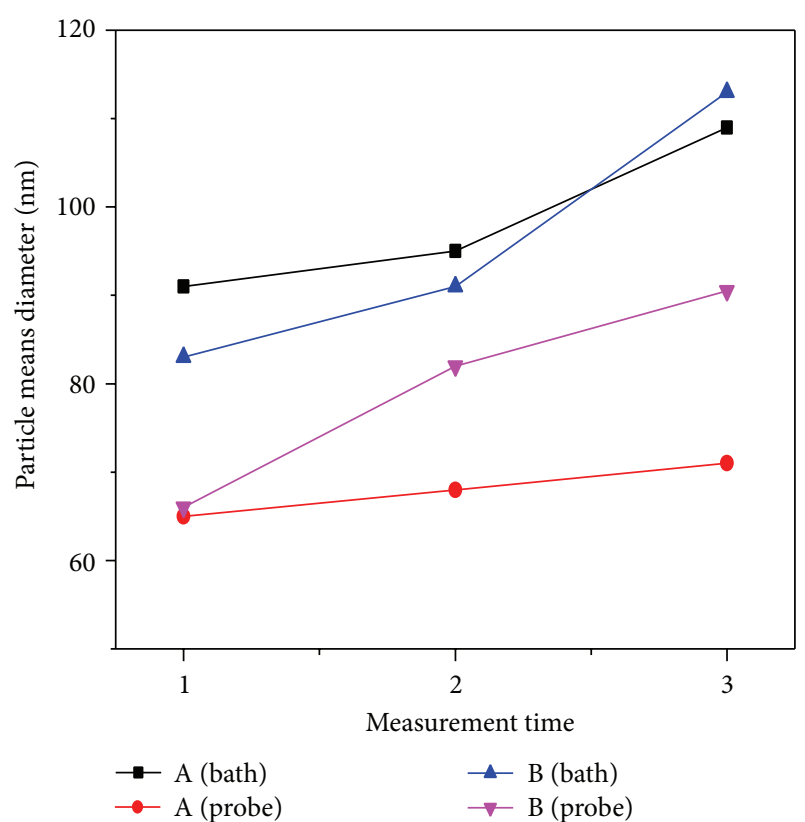

FIGURE 4: Evolution of the mean particle size for three measurements at $15 \mathrm{~min}$ intervals for NPs of sizes A and B prepared using the bath and probe sonicators.

almost ineffective in reducing the particle size, whereas the probe sonicator was highly effective (Figures 5(e) and 5(f)). As previously mentioned, in all nanofluids, the measured particle sizes were larger than the nominal particle sizes claimed by the vendor. This indicates that the oxide NPs agglomerated in DW through cohesive forces. These hard aggregates cannot be broken down into individual NPs under these operating conditions or even at very high input energy levels [22]. Comparison of the size information obtained by TEM and from the Nanophox analyzer suggests that TEM provides an average diameter of the dry particles, whereas the Nanophox analyzer provides an intensity-weighted average diameter that is always larger than the average diameter because of the hydrodynamic layer on the particles [31].

The measurement of optical absorbance is useful for understanding the dispersion behavior of particles in liquid media. Figure 6 shows the UV-vis absorption spectra of the $\mathrm{Al}_{2} \mathrm{O}_{3}$ NPs prepared in DW, without and with the use of the bath and probe sonicators for particle dispersion. The optical spectra of the original $\mathrm{Al}_{2} \mathrm{O}_{3}$ nanofluid (i.e., without sonication) as a reference exhibit strong absorption in the UV range (between 200 and $300 \mathrm{~nm}$ ) and low absorption at higher wavelengths; this is consistent with previous reports [36]. The spectral characteristics of the $\mathrm{Al}_{2} \mathrm{O}_{3}$ nanofluids prepared using the bath and probe sonicators are similar; however, there is a slight difference in the absorption edges. The sonicated samples show strong absorption below $300 \mathrm{~nm}$ and a blue shift of the absorption edge compared with the $\mathrm{Al}_{2} \mathrm{O}_{3}$ nanofluid without sonication, which can be attributed to the reduction in particle size during sonication. The absorption of $\mathrm{Al}_{2} \mathrm{O}_{3}$ particles increases after treatment with the probe sonicator; the difference in the absorption spectra between the two samples ( $\mathrm{A}$ and $\mathrm{B}$ ) may be attributed to an increased quantity of $\mathrm{Al}_{2} \mathrm{O}_{3} \mathrm{NPs}$ assembled in the fluid [36]. According to the Beer-Lambert law, there is a linear relationship between absorbance and concentration; thus, a higher concentration of NPs leads to a higher absorbance value. A higher NP concentration results in a more stable suspension, as was evident from the TEM and Nanophox results shown in Figures 5(e), 5(f), 3(b), and 3(d). For nanofluids with poor stability, the absorption was low because of particle agglomeration [37]. This spectral change indicates that NP agglomeration is considerably reduced when the probe sonicator is used.

3.2. Enhancement of Thermal Diffusivity. Figure 7(a) shows that the amplitude of the PE signal in the sample attenuates rapidly to zero with increasing frequency. The PE signal $S(f)$ decreases exponentially with increasing modulation of the frequency in the thermally thick regime of the liquid sample [33]. At frequencies below $7 \mathrm{~Hz}$, the effect of reduced thermal thickness becomes apparent; at very high frequencies, the anomalous signal is very small and independent of frequency. Therefore, the frequency range between 7 and $30 \mathrm{~Hz}$ was used for the frequency scan, which is shown in Figure 7(b). In this figure, the acquired $\mathrm{PE}$ signal is plotted as the $\ln$ (amplitude) of the PE signal as a function of $f^{1 / 2}$. In the useful frequency range, the curves are linear. The thermal diffusivity was calculated from the slope of the linear part of the $\ln$ (amplitude) of the signal curves.

Before measuring thermal diffusivity of the nanofluids, the PPE set-up was tested with DW as the base fluid. The recorded $\alpha$ value was $(1.431 \pm 0.030) \times 10^{-3} \mathrm{~cm}^{2} / \mathrm{s}$, which differs by less than $2 \%$ from the values reported in the literature [31]. The thermal diffusivity results for the $\mathrm{Al}_{2} \mathrm{O}_{3}$ nanofluids prepared using the different sonication techniques at different concentrations of NPs of sizes A and $\mathrm{B}$ are summarized in Tables 1 and 2, respectively. All values reported are the average of five measurements for each sample, and the standard deviation was calculated as an estimation of the uncertainty. The results show that the thermal diffusivity of the $\mathrm{Al}_{2} \mathrm{O}_{3}$ nanofluids is higher than that of DW [12].

The thermal diffusivity of the nanofluids is shown in Figure 8 as a function of NP concentration for the two different sized NPs and sonication systems. It is clear that, in all nanofluids, the thermal diffusivity increases gradually as the $\mathrm{Al}_{2} \mathrm{O}_{3}$ is dispersed in the DW. Moreover, in all nanofluids, a high NP concentration significantly increased the thermal diffusivity [24, 25], as shown in Figure 8 and Tables 1 and 2.

Figure 8(a) shows that the thermal diffusivity enhancement was greater for the smaller-sized NPs. This is because smaller particles have higher effective surface area to volume ratios [38]. Thus, smaller particles helped form a stable nanofluid and the probe sonicator had a substantial effect on the thermal diffusivity. At a given particle concentration, the thermal diffusivity enhancement was greater for the probe than the bath sonicator. This is because the higher power probe sonicator can effectively break large particles, generating a larger NP surface area and thus increasing the 


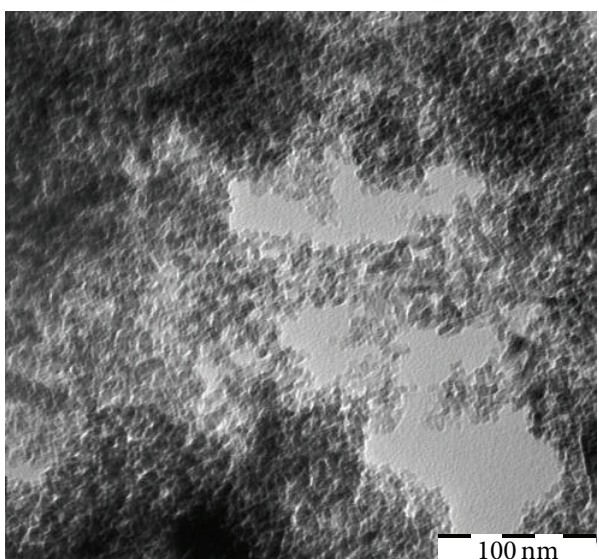

(a)

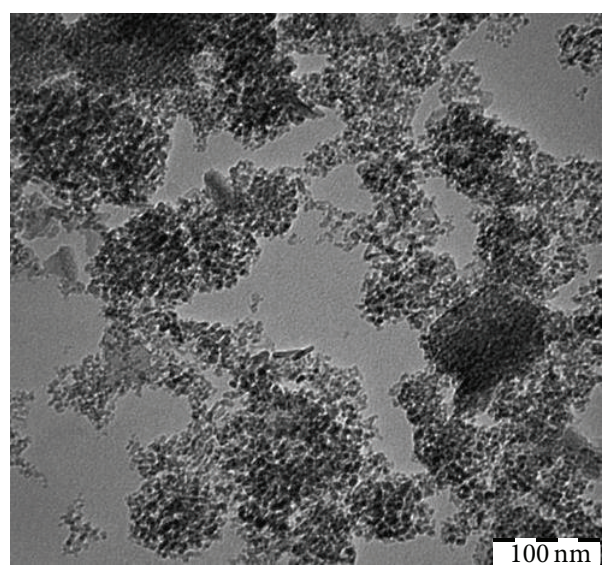

(c)

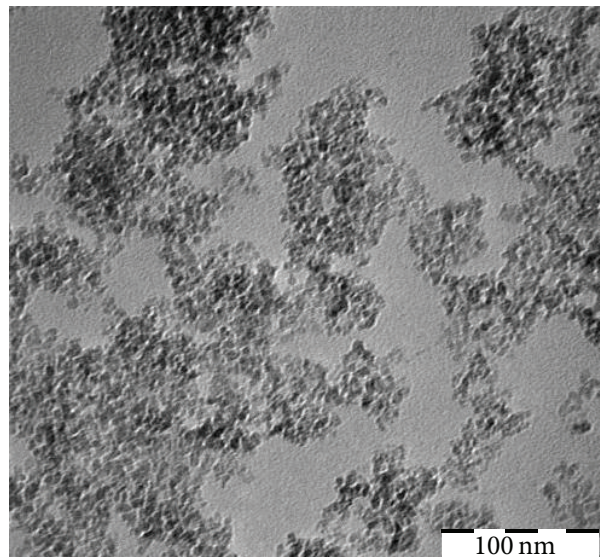

(e)

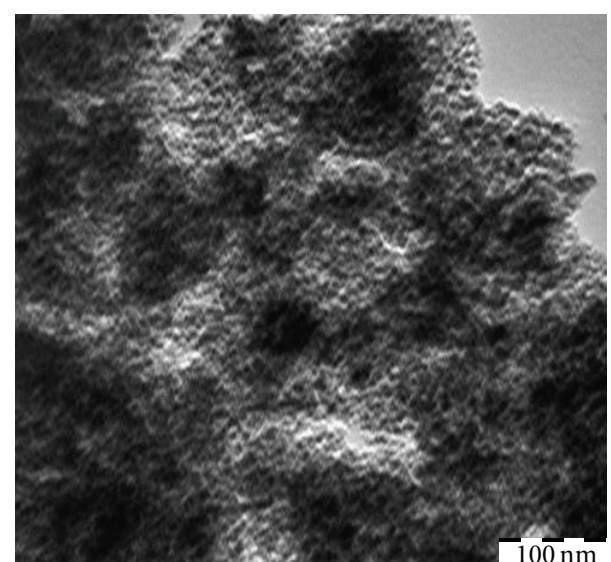

(b)

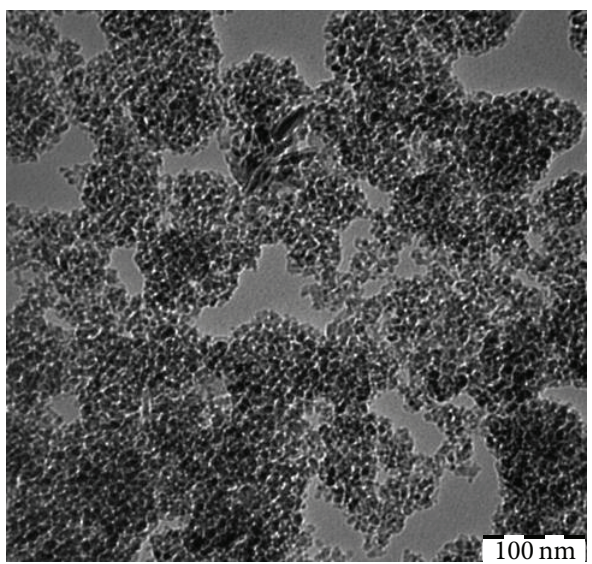

(d)

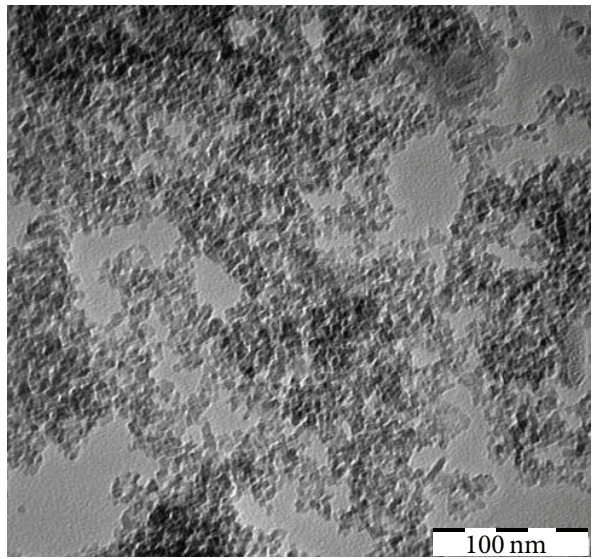

(f)

FIGURE 5: TEM images of $\mathrm{Al}_{2} \mathrm{O}_{3}$ NPs prepared in DW without ((a) and (b)) and with ((c) and (d)) the bath sonicator and ((e) and (f)) probe sonicators, for NPs of sizes A ((a), (c), and (e)) and B ((b), (d), and (f)).

thermal diffusivity. The beneficial effect of using the probe sonicator on the thermal diffusivity of $\mathrm{Al}_{2} \mathrm{O}_{3}$ nanofluids is more pronounced at a high particle concentration and small particle size. For example, the greatest enhancement of thermal diffusivity of $6 \%$ was achieved for the probe sonicator with NPs of size A at a concentration of $0.5 \mathrm{wt} \%$.
The smallest enhancement was $\approx 1 \%$ for NPs of size B at $0.125 \mathrm{wt} \%$ with the bath sonicator. These results are possibly attributable to the rapid particle clustering at a high concentration, which necessitates using a more powerful sonication tool to break up large agglomerates into smaller-sized particles. 


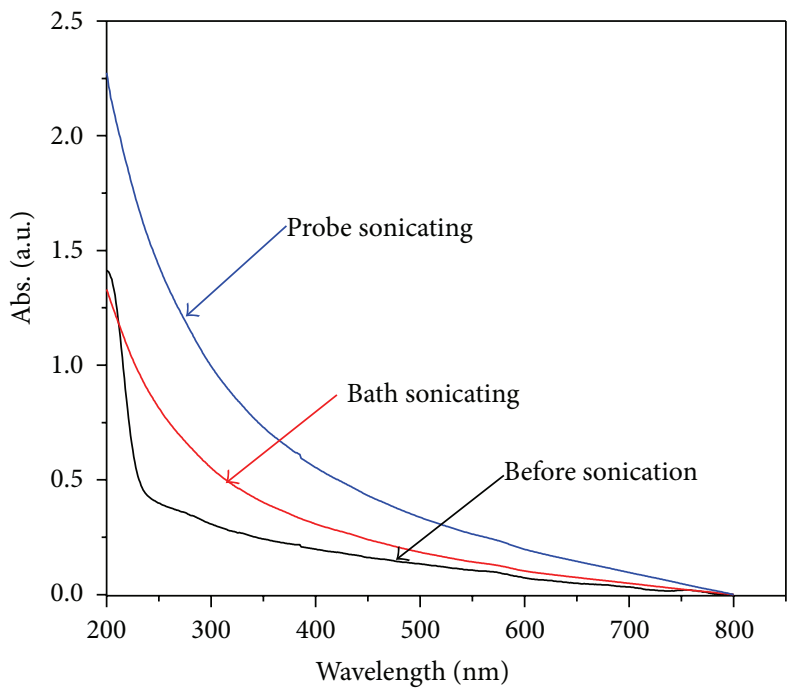

FIgURE 6: The UV-vis absorption spectra of the $\mathrm{Al}_{2} \mathrm{O}_{3}$ NPs prepared in DW without and with the bath- and probe-type sonicators for dispersion of the particles.

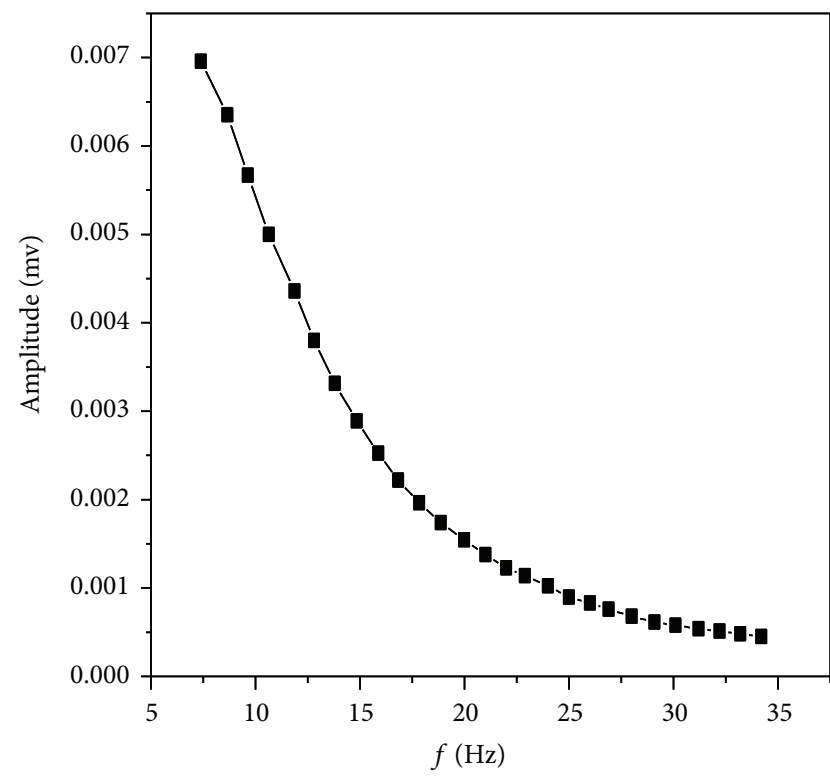

(a)

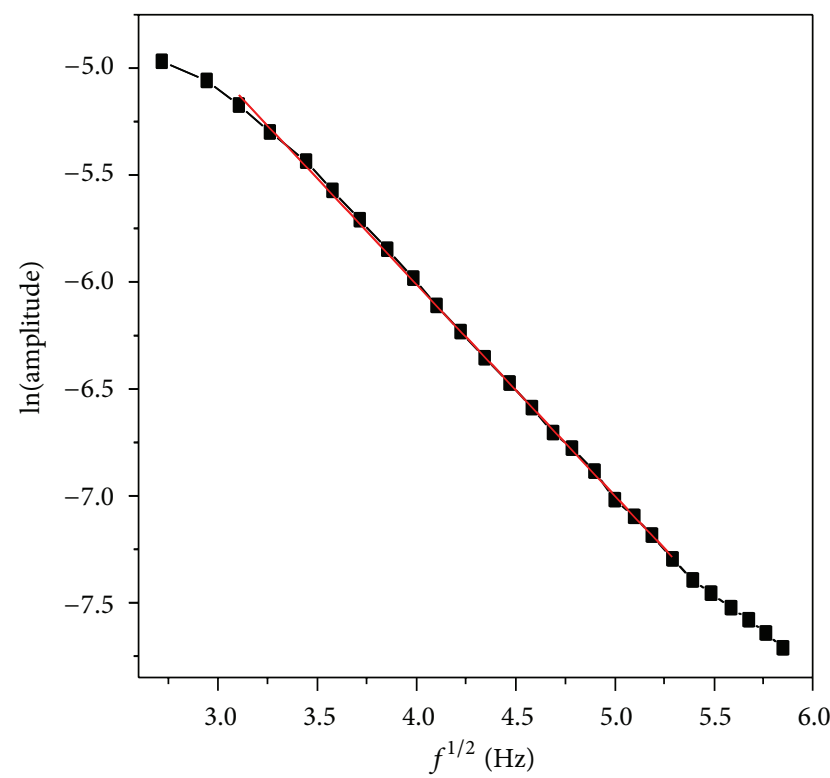

(b)

FIgure 7: (a) Amplitude of the PE signal as a function of the chopping frequency $f$ and (b) $\ln$ (amplitude) of the PE signal as a function of the square root of the chopping frequency and its fitting (2) for one of the samples.

TABLE 1: Thermal diffusivity of $\mathrm{Al}_{2} \mathrm{O}_{3}$ nanofluids, NPs type A $(11 \mathrm{~nm})$, prepared by using different sonication techniques at different NPs concentrations.

\begin{tabular}{lcccc}
\hline Concentration & \multicolumn{2}{c}{ Bath sonication } & \multicolumn{2}{c}{ Probe sonication } \\
Thermal diffusivity & $\begin{array}{c}\text { Thermal diffusivity } \\
\text { enhancement } \%\end{array}$ & $\begin{array}{c}\text { Thermal diffusivity } \\
\left(\mathrm{cm}^{2} / \mathrm{s}\right) \times 10^{-3}\end{array}$ & $\begin{array}{c}\text { Thermal diffusivity } \\
\text { enhancement } \%\end{array}$ \\
\hline 0.125 & $1.476 \pm 0.002$ & 3.1 & $1.482 \pm 0.004$ & 3.5 \\
0.25 & $1.483 \pm 0.003$ & 3.5 & $1.494 \pm 0.002$ & 4.3 \\
0.5 & $1.492 \pm 0.004$ & 4.2 & $1.515 \pm 0.003$ & 5.8 \\
\hline
\end{tabular}




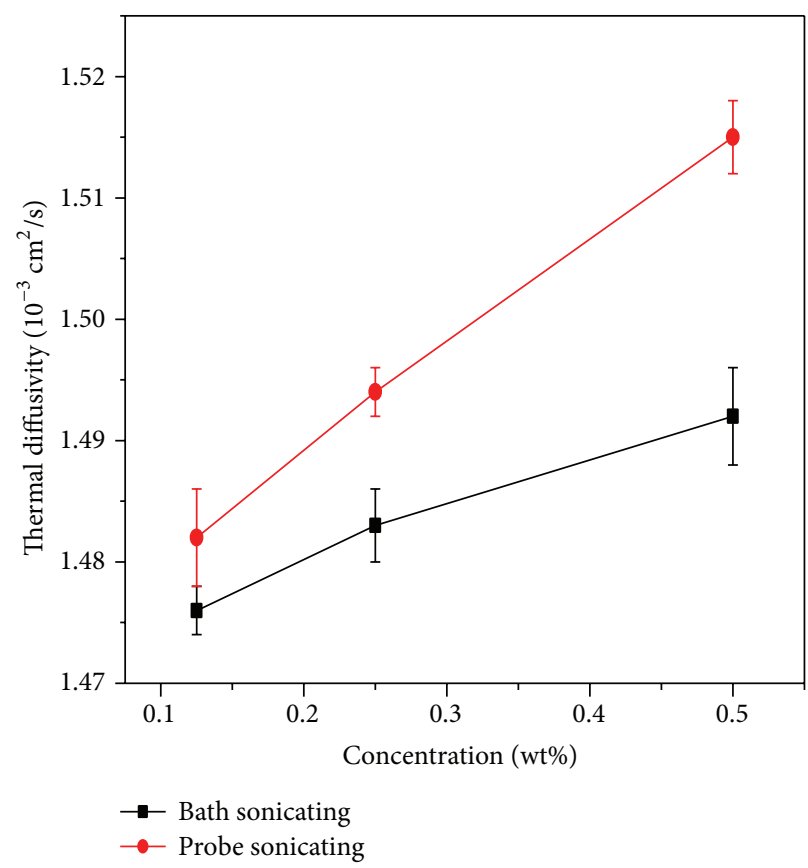

(a)

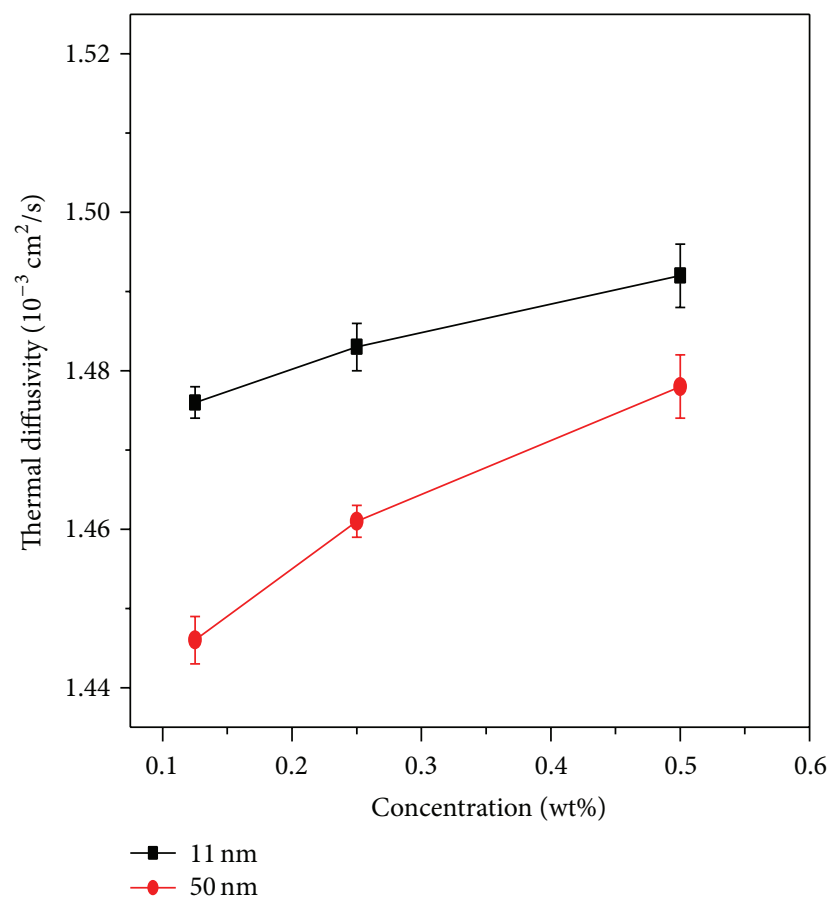

(c)

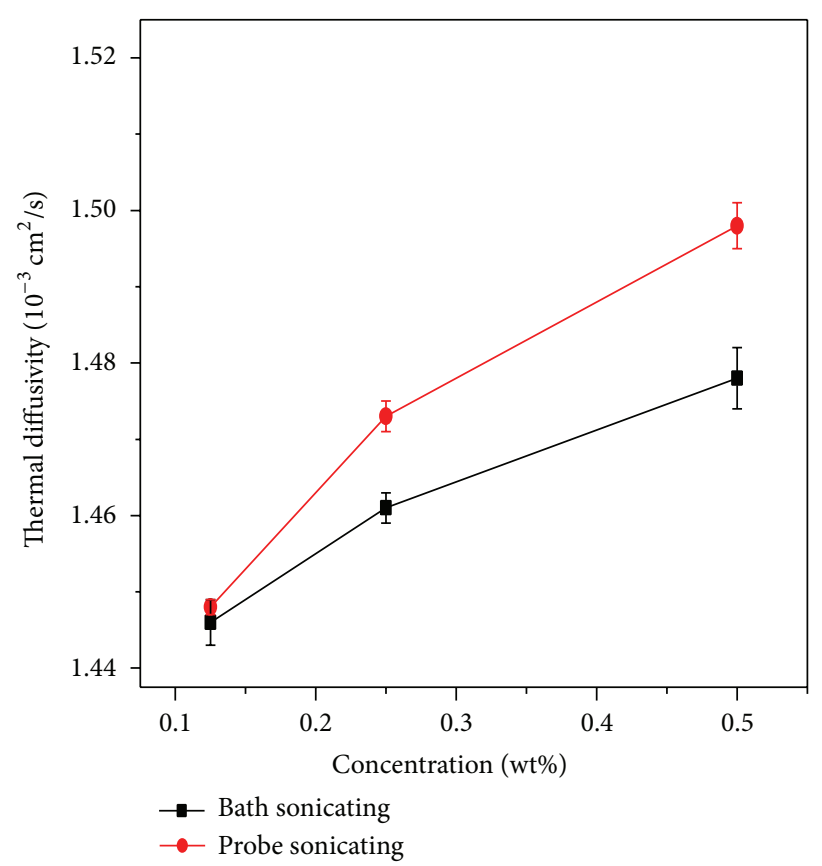

(b)

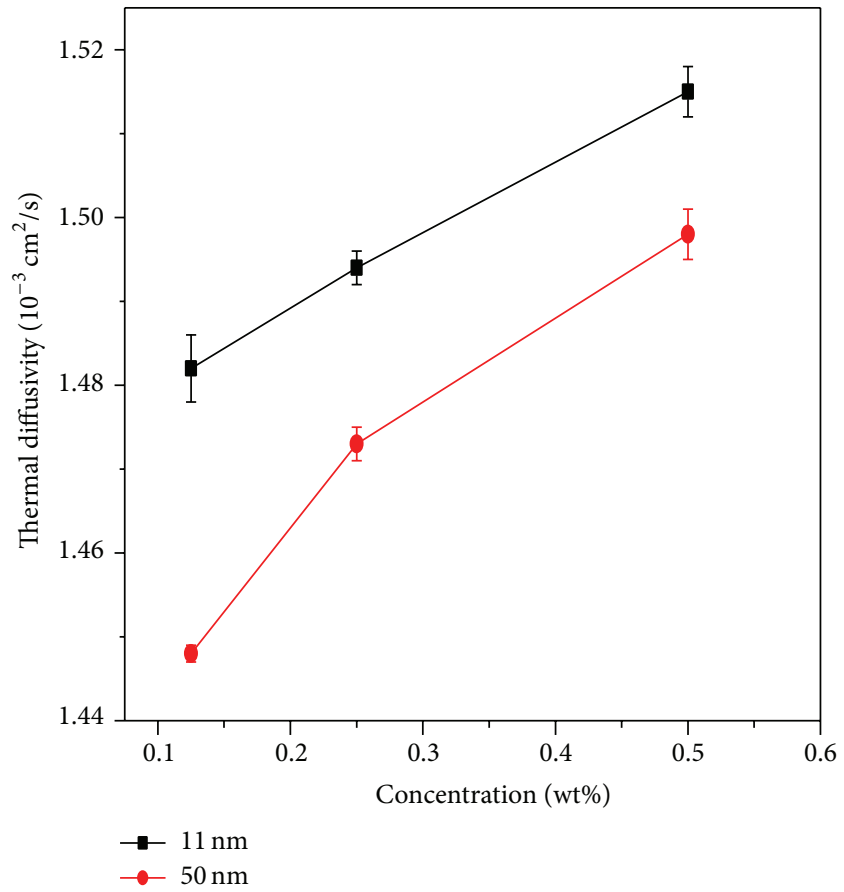

(d)

Figure 8: Several sets of data on the thermal diffusivity of $\mathrm{Al}_{2} \mathrm{O}_{3}$ nanofluids as a function of NPs concentrations ((a)-(b)) using different sonication techniques for two different NPs sizes types, (a) A and (b) B, and ((c)-(d)) for two NPs sizes, (c) bath sonicator and (d) probe sonicator.

\section{Conclusion}

In this work, $\mathrm{Al}_{2} \mathrm{O}_{3}$ nanofluids were prepared using bath and probe sonicators. The influences of sonication type and NP size and concentration on the thermal diffusivity enhancement of the nanofluids were analyzed using the
PPE technique. As expected, the enhancement in thermal diffusivity was dependent on the power of the sonication device. Moreover, the thermal diffusivity enhancement was greater with a decreased smaller particle size. Compared with the bath sonicator, use of the more powerful probe sonicator resulted in a greater thermal diffusivity enhancement and 
TABLE 2: Thermal diffusivity of $\mathrm{Al}_{2} \mathrm{O}_{3}$ nanofluids, NPs type B $(30 \mathrm{~nm})$, prepared by using different sonication techniques at different NPs concentrations.

\begin{tabular}{lcccc}
\hline Concentration & $\begin{array}{c}\text { Thermal diffusivity } \\
\left(\mathrm{cm}^{2} / \mathrm{s}\right) \times 10^{-3}\end{array}$ & $\begin{array}{c}\text { Bath } \\
\text { Thermal diffusivity } \\
\text { enhancement } \%\end{array}$ & $\begin{array}{c}\text { Thermal diffusivity } \\
\left(\mathrm{cm}^{2} / \mathrm{s}\right) \times 10^{-3}\end{array}$ & $\begin{array}{c}1.448 \pm 0.001 \\
\text { Thermal diffusivity } \\
\text { enhancement } \%\end{array}$ \\
\hline 0.125 & $1.446 \pm 0.003$ & 0.9 & $1.473 \pm 0.002$ & 1.1 \\
0.25 & $1.461 \pm 0.002$ & 2.1 & $1.498 \pm 0.003$ & 2.9 \\
0.5 & $1.478 \pm 0.004$ & 3.2 & & 4.6 \\
\hline
\end{tabular}

stability of the nanofluids. The beneficial effect of using the probe sonicator on the thermal diffusivity is more pronounced at a high particle concentration and smaller particle size, reaching about $6 \%$ at a particle concentration of about $0.5 \mathrm{wt} \%$. The thermal diffusivity measurements obtained by this technique for the $\mathrm{Al}_{2} \mathrm{O}_{3}$ nanofluids at the different concentrations and particles sizes studied are similar to those of nanofluids reported in the literature by other techniques.

\section{Conflict of Interests}

The authors declare that there is no conflict of interests regarding the publication of this paper.

\section{Acknowledgments}

The authors are grateful to the Ministry of Science, Technology and Innovation for supporting this work under the Research University Grant Scheme no. 05-02-12-1878RU. The financial support from the Universiti Kebangsaan Malaysia (UKM) with Project code DIP-2012-32 is acknowledged.

\section{References}

[1] S. Kakaç and A. Pramuanjaroenkij, "Review of convective heat transfer enhancement with nanofluids," International Journal of Heat and Mass Transfer, vol. 52, no. 13-14, pp. 3187-3196, 2009.

[2] S. Özerinç, S. Kakaç, and A. G. YazIcIoğlu, "Enhanced thermal conductivity of nanofluids: a state-of-the-art review," Microfluidics and Nanofluidics, vol. 8, no. 2, pp. 145-170, 2010.

[3] C. Kleinstreuer and Y. Feng, "Experimental and theoretical studies of nanofluid thermal conductivity enhancement: a review," Nanoscale Research Letters, vol. 6, no. 1, article 229, 2011.

[4] J. A. Eastman, S. U. S. Choi, S. Li, W. Yu, and L. J. Thompson, "Anomalously increased effective thermal conductivities of ethylene glycol-based nanofluids containing copper nanoparticles," Applied Physics Letters, vol. 78, no. 6, pp. 718-720, 2001.

[5] W. Yu, D. M. France, J. L. Routbort, and S. U. S. Choi, "Review and comparison of nanofluid thermal conductivity and heat transfer enhancements," Heat Transfer Engineering, vol. 29, no. 5, pp. 432-460, 2008.

[6] P. Keblinski, S. R. Phillpot, S. U. S. Choi, and J. A. Eastman, "Mechanisms of heat flow in suspensions of nano-sized particles (nanofluids)," International Journal of Heat and Mass Transfer, vol. 45 , no. 4 , pp. 855-863, 2001.

[7] L. Wang and J. Fan, "Nanofluids research: key issues," Nanoscale Research Letters, vol. 5, no. 8, pp. 1241-1252, 2010.
[8] S. Thomas and C. B. Panicker Sobhan, "A review of experimental investigations on thermal phenomena in nanofluids," Nanoscale Research Letters, vol. 6, article 377, 2011.

[9] J. M. Mason, U. B. Hagemann, and K. M. Arndt, "Role of hydrophobic and electrostatic interactions in coiled coil stability and specificity," Biochemistry, vol. 48, no. 43, pp. 1038010388, 2009.

[10] E. K. Goharshadi and H. Azizi-Toupkanloo, "Silver colloid nanoparticles: ultrasound-assisted synthesis, electrical and rheological properties," Powder Technology, vol. 237, pp. 97-101, 2013.

[11] C. Ying, Z. Zhaoying, and Z. Ganghua, "Effects of different tissue loads on high power ultrasonic surgery scalpel," Ultrasound in Medicine \& Biology, vol. 32, no. 3, pp. 415-420, 2006.

[12] L. P. Fallavena, F. H. F. Antunes, J. S. Alves et al., "Ultrasound technology and molecular sieves improve the thermodynamically controlled esterification of butyric acid mediated by immobilized lipase from Rhizomucor miehei," RSC Advances, vol. 4, no. 17, pp. 8675-8681, 2014.

[13] E.-Q. Xia, X.-X. Ai, S.-Y. Zang, T.-T. Guan, X.-R. Xu, and H.-B. $\mathrm{Li}$, "Ultrasound-assisted extraction of phillyrin from Forsythia suspensa," Ultrasonics Sonochemistry, vol. 18, no. 2, pp. 549-552, 2011.

[14] S. Sun, H. Zeng, D. B. Robinson et al., "Monodisperse $\mathrm{MFe}_{2} \mathrm{O}_{4}$ $(\mathrm{M}=\mathrm{Fe}, \mathrm{Co}, \mathrm{Mn})$ nanoparticles," Journal of the American Chemical Society, vol. 126, no. 1, pp. 273-279, 2004.

[15] J. Park, K. An, Y. Hwang et al., "Ultra-large-scale syntheses of monodisperse nanocrystals," Nature Materials, vol. 3, no. 12, pp. 891-895, 2004.

[16] M. C. Horrillo, J. Gutiérrez, L. Arés et al., "The influence of the tin-oxide deposition technique on the sensitivity to CO," Sensors and Actuators B: Chemical, vol. 25, no. 1-3, pp. 507-511, 1995.

[17] K. C. Grabar, R. G. Freeman, M. B. Hommer, and M. J. Natan, "Preparation and characterization of Au colloid monolayers," Analytical Chemistry, vol. 67, no. 4, pp. 735-743, 1995.

[18] E. Levashov, V. Kurbatkina, and Z. Alexandr, "Improved mechanical and tribological properties of metal-matrix composites dispersion-strengthened by nanoparticles," Materials, vol. 3, no. 1, pp. 97-109, 2010.

[19] D. Sun, Z. Y. Zhou, Y. H. Liu, and W. Z. Shen, "Development and application of ultrasonic surgical instruments," IEEE Transactions on Biomedical Engineering, vol. 44, no. 6, pp. 462-467, 1997.

[20] Y. Zou, C. Xie, G. Fan, Z. Gu, and Y. Han, "Optimization of ultrasound-assisted extraction of melanin from Auricularia auricula fruit bodies," Innovative Food Science and Emerging Technologies, vol. 11, no. 4, pp. 611-615, 2010.

[21] F. Chemat and M. K. Khan, "Applications of ultrasound in food technology: processing, preservation and extraction," Ultrasonics Sonochemistry, vol. 18, no. 4, pp. 813-835, 2011. 
[22] W. J. Parak, D. Gerion, T. Pellegrino et al., "Biological applications of colloidal nanocrystals," Nanotechnology, vol. 14, no. 7, pp. R15-R27, 2003.

[23] X. Zhang, H. Gu, and M. Fujii, "Effective thermal conductivity and thermal diffusivity of nanofluids containing spherical and cylindrical nanoparticles," Experimental Thermal and Fluid Science, vol. 31, no. 6, pp. 593-599, 2007.

[24] X. Zhang, H. Gu, and M. Fujii, "Experimental study on the effective thermal conductivity and thermal diffusivity of nanofluids," International Journal of Thermophysics, vol. 27, no. 2, pp. 569-580, 2006.

[25] R. G. Fuentes, J. A. P. Rojas, J. L. J. Pérez, and J. F. S. Ramirez, "Study of thermal diffusivity of nanofluids with bimetallic NPs with Au (core)/Ag (shell) structure," Applied Surface Science, vol. 255, no. 3, pp. 781-783, 2008.

[26] S. M. S. Murshed, K. C. Leong, and C. Yang, "Determination of the effective thermal diffusivity of nanofluids by the double hot-wire technique," Journal of Physics D: Applied Physics, vol. 39, no. 24, pp. 5316-5322, 2006.

[27] C. Kleinstreuer and Y. Feng, "Experimental and theoretical studies of nanofluid thermal conductivity enhancement: a review," Nanoscale Research Letters, vol. 6, no. 1, article 229, 2011.

[28] D. Dadarlat, C. Neamtu, V. Tosa, and M. Streza, "Accurate photopyroelectric calorimetry applied to isotopic liquid mixtures," Acta Chimica Slovenica, vol. 54, no. 1, pp. 149-153, 2007.

[29] D. Dadarlat, C. Neamtu, M. Streza et al., "High accuracy photopyroelectric investigation of dynamic thermal parameters of $\mathrm{Fe}_{3} \mathrm{O}_{4}$ and $\mathrm{CoFe}_{2} \mathrm{O}_{4}$ magnetic nanofluids," Journal of Nanoparticle Research, vol. 10, no. 8, pp. 1329-1336, 2008.

[30] M. Noroozi, B. Z. Azmi, and M. M. Moksin, "The reliability of optical fiber-TWRC technique in liquids thermal diffusivity measurement," Infrared Physics \& Technology, vol. 53, no. 3, pp. 193-196, 2010.

[31] J. B. Falabella, T. J. Cho, D. C. Ripple, V. A. Hackley, and M. J. Tarlov, "Characterization of gold nanoparticles modified with single-stranded DNA using analytical ultracentrifugation and dynamic light scattering," Langmuir, vol. 26, no. 15, pp. 1274012747, 2010

[32] J. Ordonez-Miranda and J. J. Alvarado-Gil, "Infrared emissivity determination using a thermal-wave resonant cavity: comparison between the length- and frequency-scan approaches," International Journal of Thermal Sciences, vol. 74, pp. 208-213, 2013.

[33] J. Shen and A. Mandelis, "Thermal-wave resonator cavity," Review of Scientific Instruments, vol. 66, no. 10, pp. 4999-5005, 1995.

[34] G. Pan and A. Mandelis, "Measurements of the thermodynamic equation of state via the pressure dependence of thermophysical properties of air by a thermal-wave resonant cavity," Review of Scientific Instruments, vol. 69, no. 8, pp. 2918-2923, 1998.

[35] B. Z. Azmi, M. Noroozi, Z. A. Sulaiman, Z. A. Wahab, and M. M. Moksin, "Thermal wave interferometry of gas-liquid using optical fibre thermal wave resonator cavity technique," Journal of Physics: Conference Series, vol. 214, no. 1, Article ID 012066, 2010.

[36] K. Yatsui, T. Yukawa, C. Grigoriu, M. Hirai, and W. Jiang, "Synthesis of ultrafine $\gamma-\mathrm{Al}_{2} \mathrm{O}_{3}$ powders by pulsed laser ablation," Journal of Nanoparticle Research, vol. 2, no. 1, pp. 75-83, 2000.

[37] I. L. Liu, P. Shen, and S. Y. Chen, " $\mathrm{H}^{+}$- and $\mathrm{Al}^{2+}$-codoped $\mathrm{Al}_{2} \mathrm{O}_{3}$ nanoparticles with spinel-type related structures by pulsed laser ablation in water," The Journal of Physical Chemistry C, vol. 114, no. 17, pp. 7751-7757, 2010.
[38] G. A. López-Muñoz, J. A. Balderas-López, J. Ortega-Lopez, J. A. Pescador-Rojas, and J. S. Salazar, "Thermal diffusivity measurement for urchin-like gold nanofluids with different solvents, sizes and concentrations/shapes," Nanoscale Research Letters, vol. 7, no. 1, article 667, 2012. 

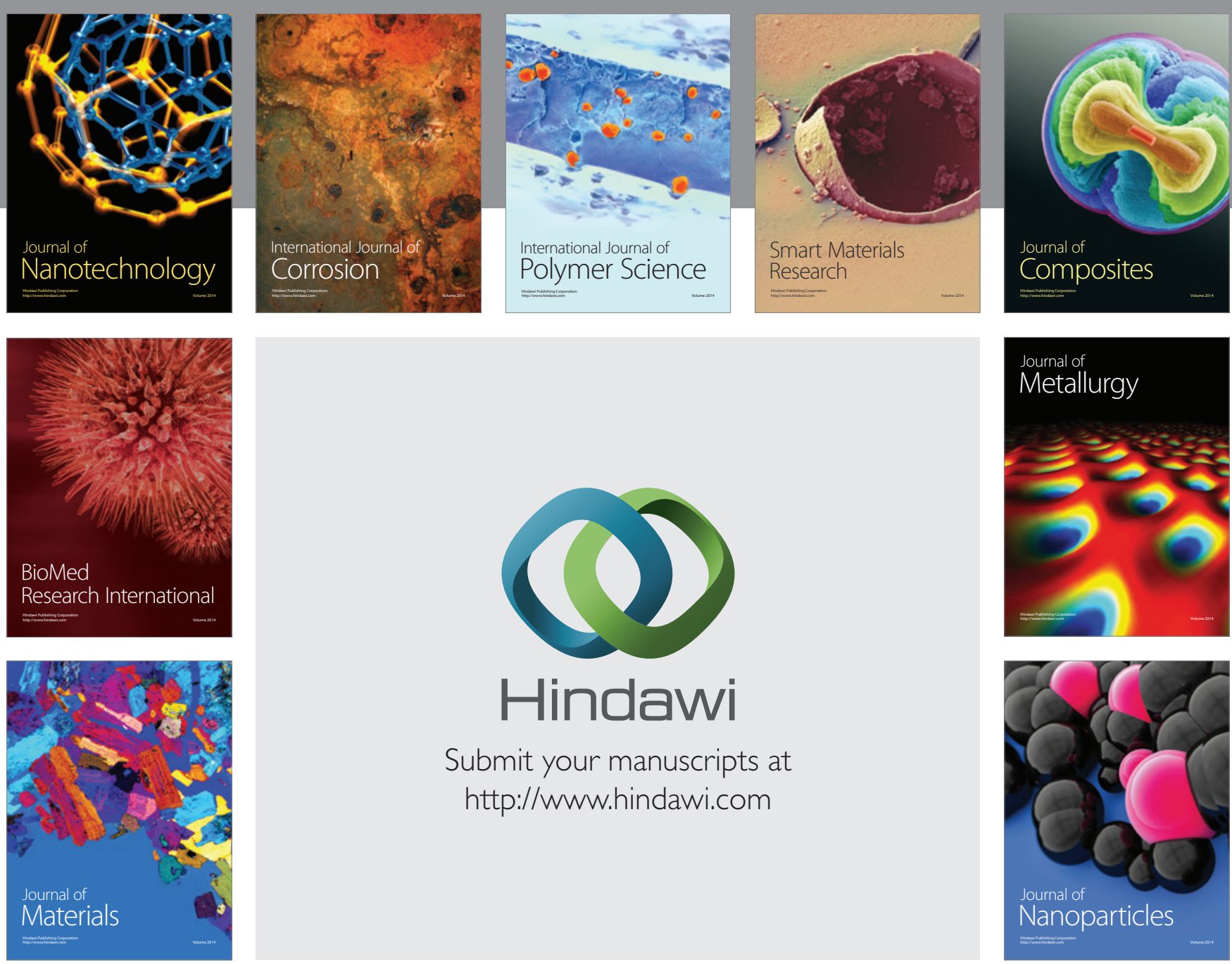

Submit your manuscripts at http://www.hindawi.com
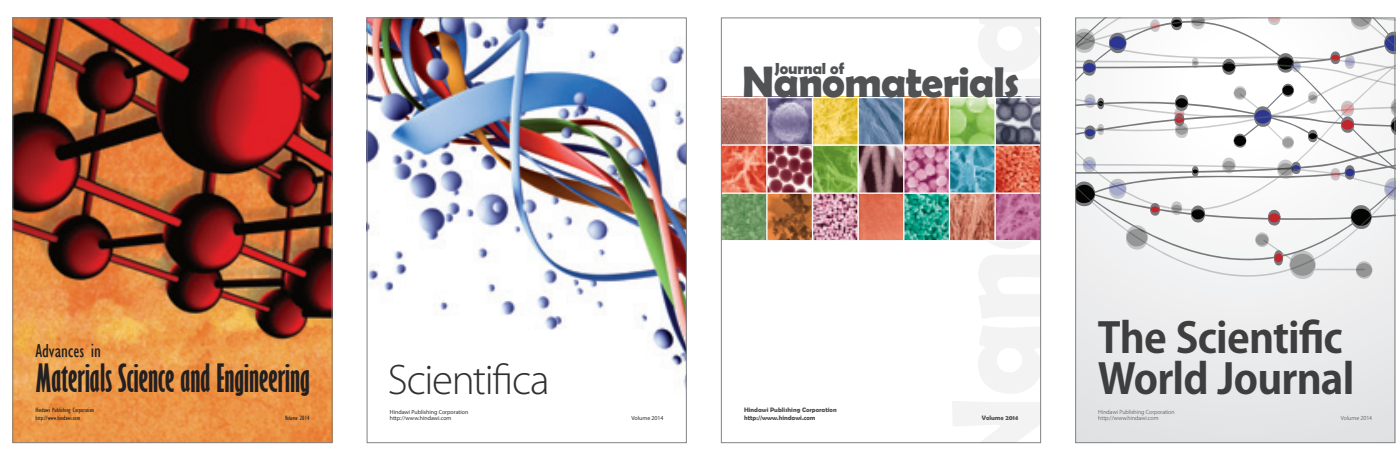

\section{The Scientific World Journal}
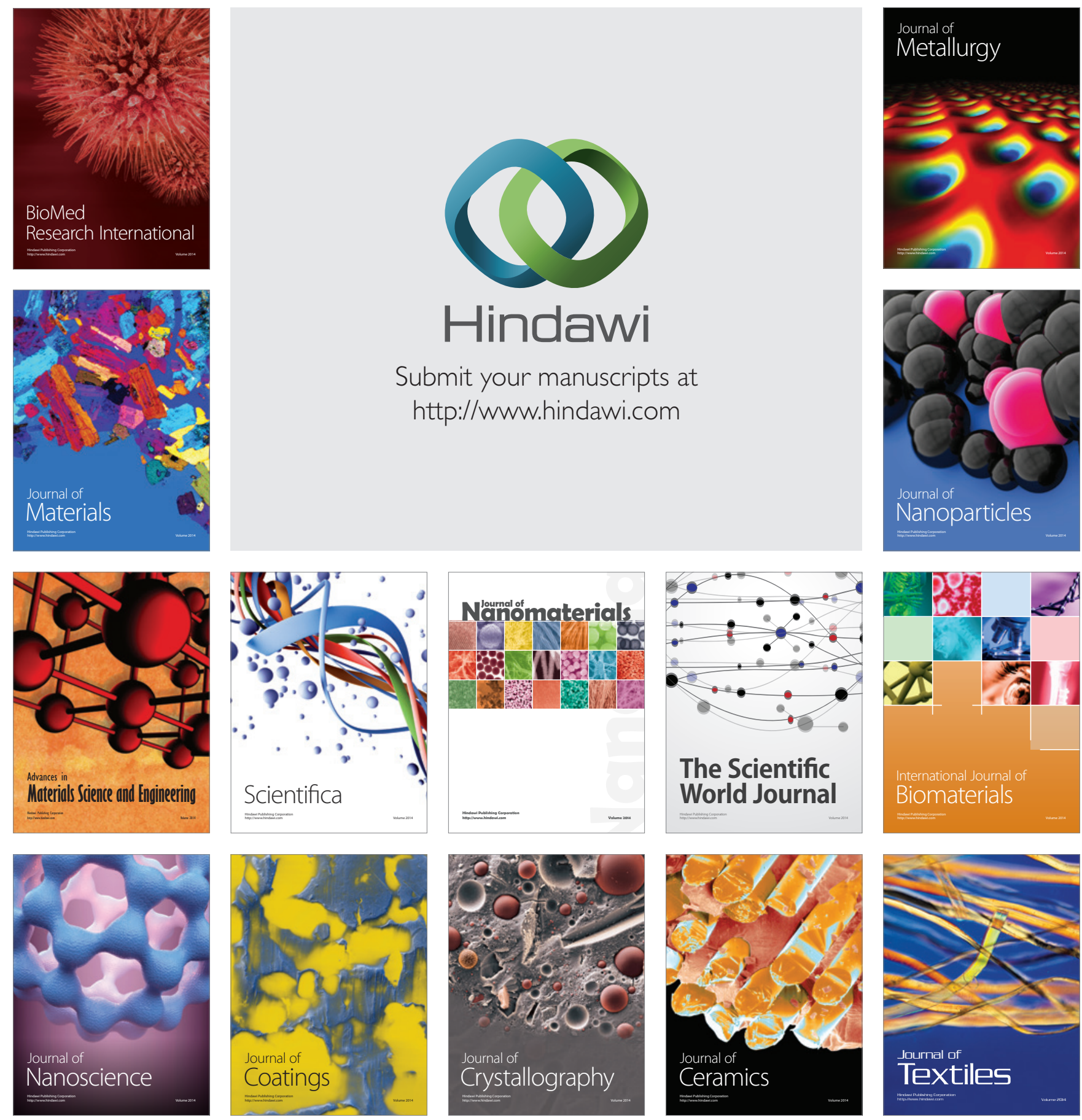